\title{
Optocase Mini AND Free Optocase for CAO Members
}

\section{Sanjay Sharma MD, MSc (Epid), FRCS}

Professor of Ophthalmology \& Epidemiology, Queen's University and Editor-in-Chief, optocase.com
A 62-year-old man presented with sudden loss of vision in conjunction with distorted vision in his right eye. He denied seeing flashing lights or new floaters or having any previous trauma. His visual acuity was $6 / 24$ in his right eye and $6 / 6$ in his left eye.

The fundus photograph is compatible with the patient having which of the following?

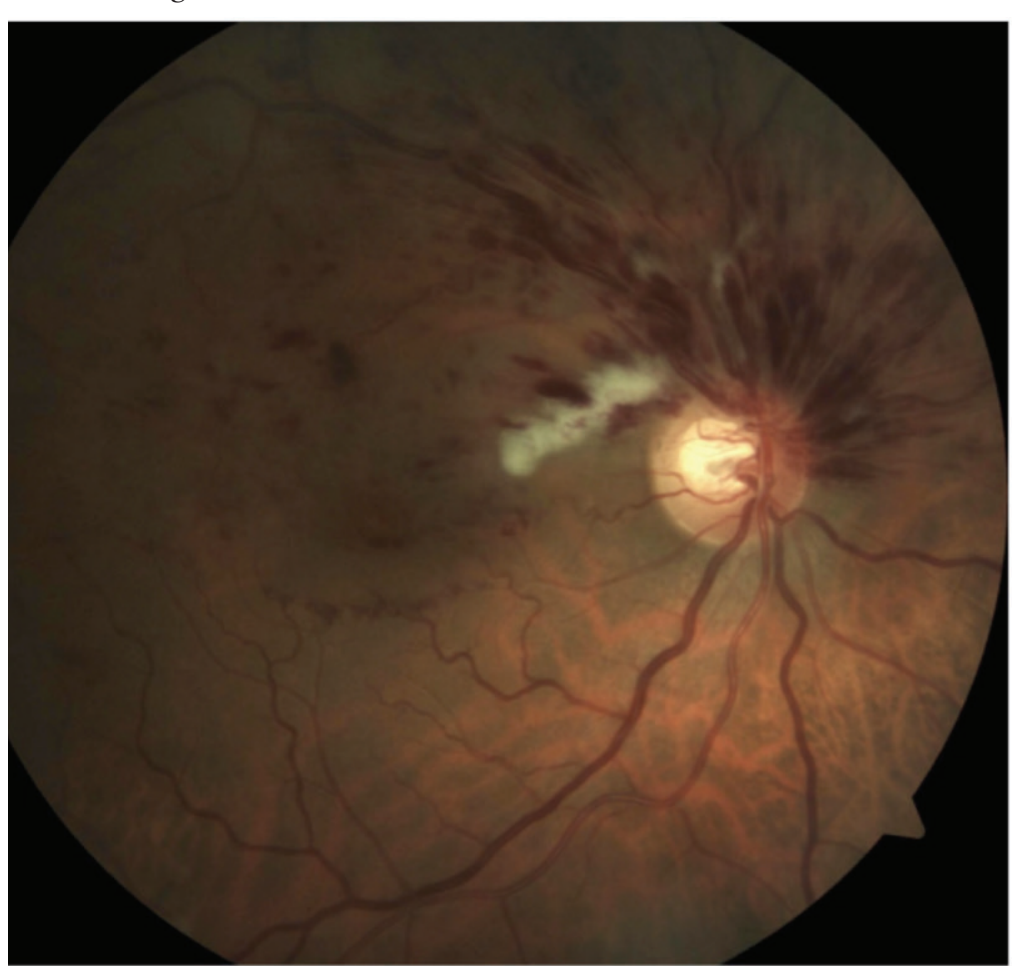

1. Branch retinal vein occlusion

2. Branch retinal artery occlusion

3. Diabetic retinopathy

4. Cytomegalovirus retinitis

Please find the answer on page 36 . 


\section{ANSWER TO OPTOCASE MINI}

\section{Branch retinal vein occlusion}

Sudden painless loss of vision is typically associated with retinal conditions. Common causes of painless loss of vision include retinal vein occlusion, retinal artery occlusion, retinal detachment, and vitreous hemorrhage.

Retinal vein occlusion can be clinically classified as branch hemi-, or central, depending on where the retinal hemorrhage is located. In central retinal vein occlusion, the hemorrhage is located in all four quadrants. In hemi-retinal vein occlusion, the hemorrhage is located in only half of the retina. In branch retinal vein occlusion, the hemorrhage is located in a specific area drained by a specific retinal venule.

Retinal vein occlusion is thought to be related to the common adventitial sheath that is shared by a retinal vein and artery. ${ }^{1}$ In almost all (99\%) patients in this condition, the artery is located anterior to the vein. ${ }^{2}$ The high differential pressure that exists between the artery and vein is though to cause the vein to collapse as it is compressed by the artery on one side and the retina on the other. This collapse causes venous return turbulence eddies that in turn lead to formation of an intravenous thrombosis at the arterial venous crossing. ${ }^{1}$ Although this is the typical pathogenic mechanism for formation of retinal vein occlusion, other factors, such as hypercoagulable states, diabetes mellitus, glaucoma, and prothrombotic conditions, could be implicated also.,3

Patients with retinal vein occlusion have a variable prognosis for improvement in vision., Poor vision can be associated with macular hemorrhage, macular edema that might complicate branch retinal vein occlusion, or vitreous hemorrhage secondary to posterior segment neovascularization. ${ }^{1}$

The Branch Retinal Vein Study, a multicentre, randomized clinical trial sponsored by the United States National Institutes of Health, demonstrated that laser photocoagulation was beneficial in two situations: when the occlusion was complicated by macular edema and a patient's visual acuity was less than $6 / 12,{ }^{4}$ and when the occlusion was complicated by formation of new blood vessels in the retina. ${ }^{5}$ More recently intravitreal injection with antiVEGF compounds and steroids have been proven to increase the risk of significant visual improvement. . $7,78^{-1}$

\section{MANAGEMENT}

The patient was referred to an ophthalmologist on an urgent basis. Dilated funduscopic examination demonstrated mild hypertensive retinopathy in the contralateral eye and a branch retinal vein occlusion in the affected eye. The patient was also noted to have substantial macular edema. He was referred to a retinal specialist, and the diagnosis of branch retinal vein occlusion with macular edema was confirmed. The patient also had a systemic workup that included blood pressure measurement; a fasting blood sugar test; prothrombin time and partial thromboplastin time test; and blood test for abnormalities in proteins C and S, antithrombin III, and a screen for a mutation in factor $\mathrm{V}$.

The patient was offered intravitreal injection with an anti-VEGF compound. After a series of injections the vision had improved to $6 / 9$.

\section{RECOMMENDATION}

Patients with sudden loss of vision should be evaluated by an ophthalmologist on an urgent basis. Patients with branch retinal vein occlusion should have a thorough systemic evaluation because many of these patients have some systemic abnormality. Patients with branch retinal vein occlusion can develop macular edema and retinal neovascularization. These complications can be treated with intravitreal injection with an anti-VEGF compound, intraocular steroids or laser photocoagulation. 
FREE OPTOCASE FOR CAO MEMBERS

\section{Learn more about hypertension and the eye, online at Optocase.com}

To learn more about how hypertension can present in the back of the eye, please consider taking the COPE-approved case study on Hypertensive Retinopathy online at www.optocase.com (worth two hours of COPE credit). The CAO has arranged that members can take the case for free until January 31, 2015 - use coupon code HRFREE on the Cases page (you will need to register for free first).

\section{REFERENCES}

1. Sharma S, Vander J. Retinal venous obstruction. In: Sharma S, Vander J. Current ocular therapy. Philadelphia, Pa: WB Saunders; 2000.

2. Zhao J, Sastry SM, Sperduto RD, Chew EY, Remaley NA. Arteriovenous crossing patterns in branch retinal vein occlusion. The Eye Disease Case-Control Study Group. Ophthalmology 1993;100:423-8.

3. Sperduto RD, Hiller R, Chew E, Seigel D, Blair N, Burton TC, et al. Risk factors for hemiretinal vein occlusion: comparison with risk factors for central and branch retinal vein occlusion. The Eye Disease CaseControl Study. Ophthalmology 1998;105:765-71.

4. Branch Retinal Vein Occlusion Study Group. Aragon laser photocoagulation for macular edema and branch vein occlusion. Am J Ophthalmol 1984;98:271-82.

5. Branch Retinal Vein Occlusion Study Group. Aragon scatter laser photocoagulation for prevention of neovascular and vitreous hemorrhage in branch vein occlusion. A randomized clinical trial. Arch Ophthalmol 1986;104:34-41.

6. Campochiaro PA, Heier JS, Feiner L, Gray S, Saroj N, Rundle AC, Murahashi WY, Rubio RG; BRAVO
Investigators. Ranibizumab for macular edema following branch retinal vein occlusion: six-month primary end point results of a phase III study. Ophthalmology 2010 Jun;117(6):1102-1112.el. doi: 10.1016/j.ophtha.2010.02.021. Epub 2010 Apr 15.

7. Campochiaro PA, Clark WL, Boyer DS, Heier JS, Brown DM, Vitti R, Kazmi H, Berliner AJ, Erickson $\mathrm{K}$, Chu KW, Soo Y, Cheng Y, Haller JA. Intravitreal Aflibercept for Macular Edema Following Branch Retinal Vein Occlusion: The 24-Week Results of the VIBRANT Study. Ophthalmology 2014 Oct 11. pii: S0161-6420(14)00790-8. doi: 10.1016/j. ophtha.2014.08.031. [Epub ahead of print]

8. Haller JA, Bandello F, Belfort R Jr, Blumenkranz MS, Gillies M, Heier J, Loewenstein A, Yoon YH, Jiao J, Li XY, Whitcup SM; Ozurdex GENEVA Study Group, Li J. Randomized, sham-controlled trial of dexamethasone intravitreal implant in patients with macular edema due to retinal vein occlusion. Ophthalmology 2011 Dec;118(12):2453-60. doi: 10.1016/j.ophtha.2011.05.014. Epub 2011 Jul 20. 